\title{
Tekrarlayan Hastane Başvurusuna Rağmen Geç Tanı Alan Nadir Bir Olgu: İnantil Hipertrofik Pilor Stenozu
}

\section{A Rare Case Received A Late Diagnosis Despite Recurrent Hospital Admissions: Infantile Hypertrophic Pyloric Stenosis}

\author{
Cüneyt Uğur ${ }^{1}(\mathbb{D})$, Enes $A y^{2}$ (D), Hasan Madenci ${ }^{3}$ (i) \\ ${ }^{1}$ Sağlık Bilimleri Üniversitesi, Konya Şehir Sağlık Uygulama ve Araştırma Merkezi, Pediatri Kliniği, Konya, Türkiye \\ ${ }^{2}$ Konya Şehir Hastanesi, Aile Hekimliği Kliniği, Konya, Türkiye \\ ${ }^{3}$ Sağlık Bilimleri Üniversitesi, Konya Şehir Sağlık Uygulama ve Araştırma Merkezi, Çocuk Cerrahi Kliniği, Konya, Türkiye
}

ORCID ID: C.U. 0000-0002-6260-7719; E.A. 0000-0002-8351-1740; H.M. 0000-0002-7243-5340

Citation/Attf: Ugur C, Ay E, Madenci H. Tekrarlayan hastane başvurusuna rağmen geç tanı alan nadir bir olgu: Infantil hipertrofik pilor stenozu. Çocuk Dergisi - Journal of Child 2021;21(2):212-214. https://doi.org/10.26650/jchild.2021.816515

öz

Infantil hipertrofik pilor stenozu pilorun hipertrofisi nedeniyle pilor kanaIının daralmasıdır. Hastalık bebeklerde beslenmeyi takiben ortaya çıkan fışkııır tarzda ve safrasız kusma ile kendini gösterir. Erken tanı konulamayıp tedavide geç kalınması halinde dehidratasyon, ciddi beslenme bozukluğu, kilo kaybı ve asit-baz dengesizliği gelişebilir, hatta ölümle sonuçlanabilir. Biz bu olgu sunumunda üç gündür devam eden safrasız kusma ve karında şişlik şikayeti ile acil servise başvuran üç ay sekiz günlük erkek bebeği sunuyoruz.

Anahtar Kelimeler: Bebek, infantil hipertrofik pilor stenozu, kusma

\section{GiRiş}

İnfantil hipertrofik pilor stenozu (IHPS), pilorik düz kas liflerinin hiperplazisine bağlı olarak pilor kanalının daralmasıdır (1). Kızlara oranla erkeklerde 4 kat daha fazla rastlanmaktadır. IHPS, yenidoğan döneminde görülen mide çıkışı darlıklarının en sık nedenidir. Klasik olarak, doğum sonrası bir sıkıntısı olmayan 3-6 haftalık infantlarda beslenmeyi takiben fişkırır tarzda ve safrasız kusma ile kendini gösterir. Bu kusmaların sıklığı giderek artar. Erken teşhis edilemeyen olgularda ciddi beslenme bozukluğu, dehidratasyon, asit-baz dengesizliği ve kilo kaybı ortaya çıkabilir; tedavide geç kalınması durumunda ölüm gerçekleşebilir $(2,3)$.

Teşhis genelde ayrıntılı öykü ve dikkatli fizik muayene ile konulmaktadır. Teşhisten emin olunamayan durumlarda ultrasonografi (USG) ve kontrastlı pasaj grafisi ayırıcı tanıda kullanılmaktadır. Tedavisi cerrahidir ve en sık olarak 1912'de
ABSTRACT

Infantile hypertrophic pyloric stenosis is the narrowing of the pyloric duct due to hypertrophy of the pylorus. The disease manifests itself with gushing and non-bile vomiting in babies after feeding. If early diagnosis is not provided and treatment is delayed, dehydration, severe malnutrition, weight loss and acid-base imbalance may develop, and may even result in death. In this case report, we present a three-month and eight-day-old male baby who was admitted to the emergency department with complaints of non-bile vomiting and abdominal distension for three days.

Keywords: İnfant, infantile hypertrophic pyloric stenosis, vomiting

Ramstedt tarafindan tanımlanan ekstramukozal piloromyotomi ameliyatı uygulanmaktadır $(3,4)$. Bu olgu, safrasız kusma şikayeti ile tekrarlayan hastane başvurusu olan ve aynı zamanda kilo alımı yetersiz olan bebeklerde ayırıcı tanıda iHPS'nin de düşünülmesi gerektiğini vurgulamak amacıyla sunulmuştur.

\section{OLGU SUNUMU}

Üç ay sekiz günlük erkek bebek üç gündür şiddetlenen safrasız kusma ve karında şişlik şikayeti ile acil servisimize başvurdu. Hastanın safrasız kusma şikayetinin doğumdan üç-dört gün sonra başladığı, hafif şiddette sürekli devam ettiği, hastanın bu nedenle daha önce mükerrer poliklinik ve acil servis başvuruları olduğu ve gastroözefageal reflü hastalı̆̆ (GÖRH) tanısı ile tedavi aldığı öğrenildi. Öyküsünde; 38. gestasyonel haftada sezaryen ile 5050 gr (97 p) olarak doğduğu, başka sağlık probleminin olmadığı, anne ve babasında bilinen bir hastalık olmadığı öğrenildi.

Sorumlu Yazar/Corresponding Author: Cüneyt Uğur E-mail: cugur70@gmail.com

Başvuru/Submitted: 26.10.2020 • Revizyon Talebi/Revision Requested: 01.03.2021 • Son Revizyon/Last Revision Received: $01.03 .2021 \bullet$ Kabul/Accepted: 13.03 .2021 
Hastayı acil servisteki değerlendirdiğimizde; vücut ağırlığı 5400 gr (10-25 p), boy $59 \mathrm{~cm}$ (10-25 p), baş çervresi $41 \mathrm{~cm} \mathrm{(25-50}$ p), vücut sıcaklığı $36,7^{\circ} \mathrm{C}$, kan basıncı: $80 / 50 \mathrm{mmHg}$, nabız 110/ dakika, solunum sayısı 32/dakika ve pulse oksimetre ile oksijen saturasyonu \%97 olarak saptandı. Fizik muayenesinde hastanın bilinci açık, hafif dehidrate, cilt turgoru hafif azalmış, batında belirgin distansiyon mevcuttu. Batın muayenesinde hassasiyet, rebound ve defans tespit edilmedi. Ayrıca yeterli kilo almadığı tespit edildi. Diğer sistem muayeneleri doğaldı.

Hastanın acil serviste bakılan tetkiklerinde; tam kan sayımında lökosit sayısı $22.540 / \mathrm{mm}^{3}$, hemoglobin $9.5 \mathrm{gr} / \mathrm{dl}$, trombosit $651.000 / \mathrm{mm}^{3}$, C-reaktif protein 0,69 mg/L, glukoz $86 \mathrm{mg} /$ $\mathrm{dL}, \mathrm{Na} 138 \mathrm{mmol} / \mathrm{L}, \mathrm{K} 4 \mathrm{mmol} / \mathrm{L}, \mathrm{Cl} 100 \mathrm{mmol} / \mathrm{L}$, aspartat aminotranferaz $47 \mathrm{U} / \mathrm{I}$, alanin aminotransferaz $24 \mathrm{U} / \mathrm{L}$ olarak saptandı. Kan gazı tetkikinde: pH 7.42, PCO2 37.9 mmHg, $\mathrm{HCO} 3$ $24.5 \mathrm{mmol} / \mathrm{L}$ idi. Böbrek fonsiyon testleri, kalsiyum, fosfor ve idrar incelemesi normal bulundu. İdrar kültüründe üreme olmadı. Ayakta direk batın grafisinde (ADBG) dilate ve geniş mide saptandı (Şekil 1). Hastanın abdomen USG'sinde pilor kanal uzunluğu 25 mm, pilor duvar kalınlığı 18 mm olarak ölçüldü.

Hastaya IHPS tanısı konularak piloromyotomi ameliyatı yapıldı. Hipertrofik pilorun ameliyat esnasında görünümü Şekil 2'de görülmektedir. Intravenöz dengeli elektrolit sıvısı alan hasta sekiz saat sonra oral beslenmeye başlandı. Beslenmeyi tolere eden hasta postop 36. saatte taburcu edildi. Kontrole gelen hastada ameliyat sonrası herhangi bir komplikasyon tespit edilmedi.

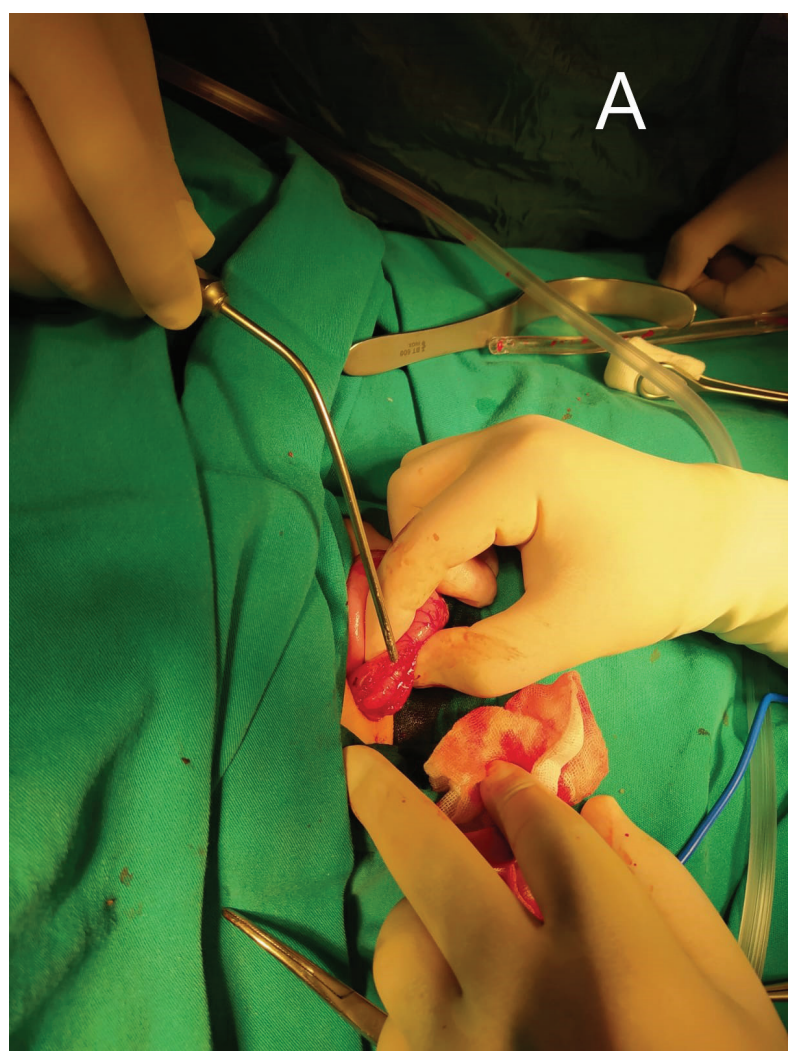

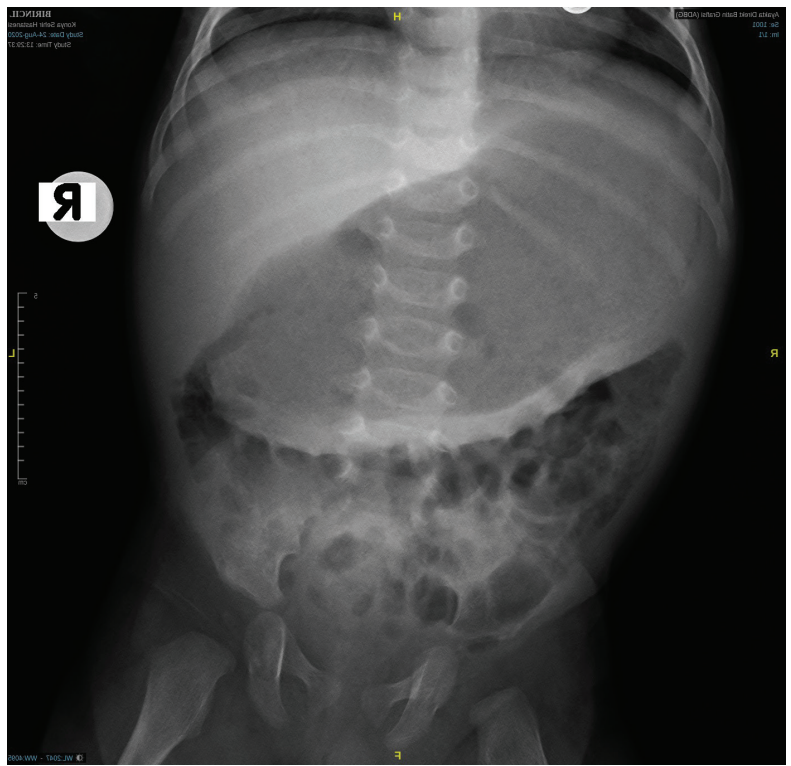

Şekil 1: Ayakta direk batın grafisinde geniş ve dilate mide görüntüsü.

\section{TARTIŞMA}

IHPS'nın etiyolojisi henüz tam olarak açıklanamamıştır. İnsidansı Amerika'da 1000'de iki olarak saptanmış olup, beyaz ırktaki oranı 300-900 canlı doğumda bir, Afrika ve Asya kökenlilerde daha nadir olarak görülmektedir $(3,5,6)$. Hastalığın görünür

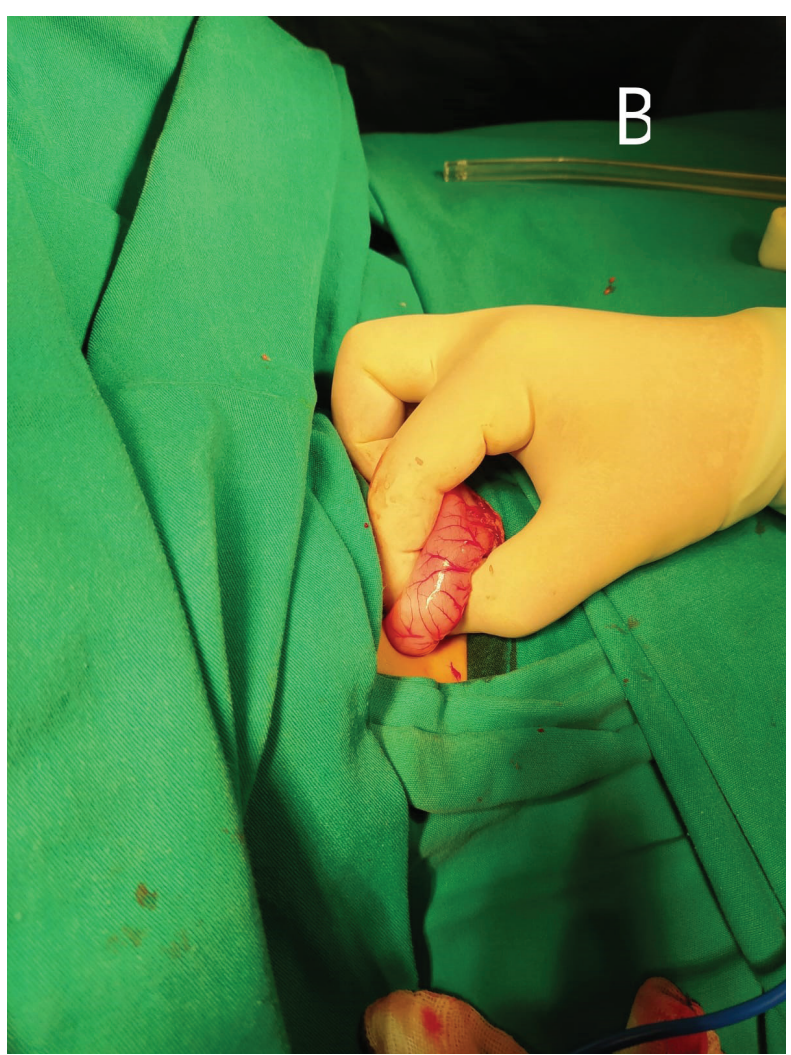

Şekil 2A ve 2B: Ameliyat esnasında hipertrofik pilorun görüntüsü. 
peristaltizm, palpabl pilor kitlesi, fişkırır tarzda kusma şeklinde triadı vardır. Triadın varlığında IHPS tanısı doğrudan ve kolayca konabilmesine rağmen hastaların sadece $1 / 3$ 'ünde bu triad görülebilir (1). Özellikle bu triadın görülmediği durumlarda hastalık gastroözefageal reflü ile kolaylıkla karışır ve GÖRH ile ayrıcı tanısının yapılması oldukça zorlaşır. Olgumuzda klasik triadtan sadece fişkırır tarza kusma mevcuttu ve olgumuzun iki kez GÖRH tanısı ile tedavi öyküsü bulunmaktaydı. Literatürde IHPS'nin nadiren uzamış sarılık ve özefagus atrezisi ile birlikteliği gösterilse de olgumuzda sarılık öyküsü yoktu ve özefagus atrezisi saptanmadı $(7,8)$.

Abdomen USG'de pilor kanal uzunluğunun $>16 \mathrm{~mm}$ ve pilor duvar kalınlığının >4 mm olması İHPS tanısı lehine yorumlanır. Abdominal USG tanı için elverişli ve hassas bir modalite olmasına karşın tanının fizik muayene ile de doğrulanması önemlidir $(3,9)$. Olgumuzun abdomen USG'sinde pilor duvar kalınlığı $18 \mathrm{~mm}$, pilor kanal uzunluğu $25 \mathrm{~mm}$ olarak ölçüldü. Ayrıca hastamızın ADBG'sinde geniş ve dilate bir mide görüntüsü saptandı. USG ve ADBG bulgusu IHPS tanısı için yeterli görülüp kontraslı duodenum grafisine gerek kalmamıştir.

IHPS'li olgularda hipokloromik, hipokalemik alkaloz olması beklenir (10). Türkiye'de yapılan bir çalışmada IHPS'li hastaların \%67'sinde pH 7,42 olarak saptanmıştr (3). Bizim olgumuzda da $\mathrm{pH}$ 7,42 olarak saptandı. Hastalarda ayrıca dehidratasyon ve kilo kaybı görülebilmektedir (11). Olgumuzda hafif dehidratasyon mevcuttu. Doğum ağırlığı 5050 gr, mevcut vücut ağırlığı 5400 gr idi ve bu durum hastamızın yeterli kilo alamadığını göstermekteydi.

Tedavide son yıllarda laparoskopik piloroplasti ve sirkumumbilikal kesi uygulamalarını tercih edenler de olmaktadır $(12,13)$. En sık olarak Ramstedt piloromyotomi tekniği uygulanmaktadır (3). Olgumuz da bu teknik ile ameliyat edildi.

Sonuç olarak IHPS, tanısı erken konulmaz ve bir an önce cerrahi olarak tedavi edilmezse ağır dehidratasyon, ciddi beslenme bozukluğu, kilo kaybı ve asit-baz dengesizliği ile seyredebilen hatta ölümle sonuçlanabilen bir hastalıktır. Safrasız kusma şikayetiyle tekrarlayan hastane başvurusu olan ve aynı zamanda kilo alımı yetersiz olan bebeklerde ayırıcı tanıda iHPS akla getirilmeli ve özellikle GÖRH ile ayırıcı tanısı yapılmalıdır.

Bilgilendirilmiş Onam: Katılımcılardan bilgilendirilmiş onam alınmıştır.

Hakem Değerlendirmesi: Dış bağımsız.

Yazar Katkıları: Çalışma Konsepti/Tasarım- C.U.; Veri Toplama- E.A.; Veri Analizi/Yorumlama- C.U., E.A., H.M.; Yazı Taslağı- C.U., E.A.; İçeriğin Eleştirel İncelemesi- C.U., E.A., H.M.; Son Onay ve Sorumluluk- C.U., E.A., H.M.
Çıkar Çatışması: Yazarlar çıkar çatışması beyan etmemişlerdir.

Finansal Destek: Yazarlar finansal destek beyan etmemişlerdir.

Informed Consent: Written consent was obtained from the participants.

Peer Review: Externally peer-reviewed.

Author Contributions: Conception/Design of Study- C.U.; Data Acquisition- E.A.; Data Analysis/Interpretation- C.U., E.A., H.M.; Drafting Manuscript- C.U., E.A.; Critical Revision of Manuscript- C.U., E.A., H.M.; Final Approval and Accountability- C.U., E.A., H.M.

Conflict of Interest: Authors declared no conflict of interest.

Financial Disclosure: Authors declared no financial support.

\section{KAYNAKLAR/REFERENCES}

1. Ndongo R, Tolefac PN, Tambo FFM, Abanda MH, Ngowe MN, Minkande JZ. Infantile hypertrophic pyloric stenosis: a 4 year experience from two tertiary care centres in Cameroon. BMC Res Notes 2018;11:1-5.

2. Usta Y, Uslu N, Gürakan F, Yüce A, Talim B, Ekinci S ve ark. Geç bulgu veren hipertrofik pilor stenozu: Bir vaka takdimi. Çocuk Sağlığı ve Hast Derg 2007;50:199-200.

3. Aydoğdu B, Sander S, Demirali O, Güvenç Ü, Başdaş CB, Kuzdan MÖ ve ark. Infantil Hipertrofik Pilor Stenozu: Çocuklarda En Sık Safrasız Kusma Nedeni. JOPP Derg 2012;4(2):69-73.

4. Ramstedt C. Zur operation der angeborenen pylorus-stenose. Med Klin 1912;8:1702-3.

5. To T, Wajja A, Wales PW, Langer JC. Population demographic indicators associated with incidence of pyloric stenosis. Arch Pediatr Adolesc Med 2005;159:520-5.

6. Pandya S, Heiss K. Pyloric stenosis in pediatric surgery: an evidencebased review. Surg Clin North Am 2012;92:527-39.

7. Kazez A, Demirbag B. Özefagus Atrezisi ve Pilor Stenozu Birlikteliği: Olgu sunumu. Erciyes Tıp Dergisi 1997;19(3):190-2.

8. Engin MMN, Özkan A, Kılıçaskan Ö, Kaya F, Temizkan RC, Kocabay K. Yenidoğanda Uzamış Sarılığın Nadir ve Önemli Bir Sebebi: İnfantil Hipertrofik Pilor Stenozu. Sakarya Tıp Dergisi. 2018;8(4):854-8.

9. Huang $\mathrm{YL}$, Lee $\mathrm{HC}$, Yeung $\mathrm{CY}$, Chen $\mathrm{WT}$, Jiang $\mathrm{CB}$, Sheu JC, et al. Sonogram before and after pyloromyotomy: the pyloric ratio in infantile hypertrophic pyloric stenosis. Pediatr Neonatol 2009;50:117-20.

10. Schwartz MZ. Hypertrophic Pyloric Stenosis. In: O'Neill J, Rowe M, Grosfeld JL et al, eds. Pediatr Surgery.st.Louis, Missour: Mosby-Year Book. 1998;1111-8.

11. Puri P, Lakshmanadoss G. Hypertrophic pyloric. In: Puri P. Newborn Surgery. Editor. Oxford, England: Butter-Worth-Heinemann; 1996; p 266-71.

12. Alain JL, Grousseau D, Longis B, Ugazzi M, Terrier G. Extramucosal pyloromyotomy by laparoscopy. Eur J Pediatr Surg 1996;7:10-2.

13. Sarımurat N, Celayir S, Kılıç N, Bozkurt P. Sirkumumblikal kesi ile piloromiyotomi. Pediatrik Cerrahi Dergisi 1996;10:92-4. 